\title{
Improving antidepressant drugs: update on recently patented compounds
}

\begin{abstract}
Background: According to the World Health Organization, depression is a common condition that affects about 121 million people worldwide. Although the pathophysiological origin of this condition is still unknown, most of the known antidepressants enhance the extracellular availability of brain monoamines (serotonin and/or noradrenaline).

Objective/Method: We have searched for the potential drugs and targets being addressed in the most recent patents. Hence, we have explored the Patent Database of the European Patent Office using the esp@cenet searching engine for the period 2005-2008, looking for "antidepressants". In addition, a search in the Medtrack database yielded information on pharmaceutical companies developing compounds as antidepressants, market size and their market prospects.

Conclusions: We have found that, in general, the preferred targets to develop antidepressants continue to be those aiming the serotoninergic system and, in a less extend, the noradrenergic one; but, more particularly, those that aim multiple targets are preferred due to problems concerning the efficacy of highly selective drugs. Additionally, a small number of new systems are being targeted, such as the melatonergic. However, when looking at the pharma-market and the antidepressants in the pipeline a new trend is observed developing dual-action drugs that could be used in depression and schizophrenia therapy.
\end{abstract}

\section{KEYWORDS}

Antidepressants, SSRI, SNRI, a2-adrenoceptor antagonist, 5-HT antagonist, fluoxetine, mirtazapine, schizophrenia, glycinergic system, melatonin, multi-target drugs. 


\section{INTRODUCTION}

According to the World Health Organization, depression is a common condition that affects about 121 million people worldwide. ${ }^{1}$ Moreover, neuropsychiatric disorders are the second largest cause of disease burden in the world after cardiovascular diseases, and the number of people affected with these disorders is likely to increase further as the population ages. The economic costs to society are enormous, with one estimate from the International Labour Organization placing them at 3-4\% of the gross national product (GNP) in EU member states. ${ }^{2}$ The high cost of care and loss of workplace productivity are due to lack of treatment or limitations of currently used drugs.

The pathophysiological origin of this disease continues to be unknown and it was not until the mid 1960s that a biochemical explanation for the phenomenon became accepted. The monoamine theory, the most widely accepted, ${ }^{3}$ states that depression is a result of a deficiency of brain monoamine (noradrenaline -NA- and/or serotonin -5-HT-) activity and that an approach to treat depression is to enhance this monoaminergic activity. In a normal brain, neurotransmitters such as NA or $5-\mathrm{HT}$ are liberated in the synapse by the presynaptic neuron. While in the synapse, the neurotransmitter can interact with the postsynaptic neuron to exert its normal effect, it can be metabolized or it can be reuptaken by the presynaptic neuron. As well, in the synapse, the neurotransmitter can interact with some receptors in the presynaptic neuron, known as autoreceptors, which inhibit its activity. Therefore, possible approaches towards increasing the monamine level in the brain would be:

(a) to block the presynaptic inhibitory autoreceptors, mostly the $a_{2}$-adrenoceptors $\left(a_{2}\right.$ $A R$ ), and some of the $5-\mathrm{HT}$ subtype receptors (1A or $1 B$ ),

(b) to block the monoamine reuptake mechanisms from the synapse, by means of $5-\mathrm{HT}$ or NA reuptake inhibitors: SSRIs, SNRIs, or NRIs,

(c) to inhibit the metabolic pathways (monoamine oxidase inhibitors, MAOIs),

(d) to act directly on monoaminergic neuron activity.

What is usually considered to be the first generation of antidepressants was developed after the Second World War, and some of the most important compounds developed during this period were found by serendipity. The first two types of drugs used for the treatment of major depression were the MAOIs and the tricyclic antidepressants. 
Iproniazid, which can be considered the first modern antidepressant, is a MAOI and was originally developed as an antituberculosis drug in the 1950s. After promising preliminary results, this compound was prescribed to patients with major depression from 1957. Although it is no longer used because of toxic side effects, it led to further research in the idea of using drugs to alleviate depression. The first tricyclic antidepressant developed was Imipramine, which was conceived originally for the treatment of schizophrenia. Later on different studies showed that this drug increased the monoamine activity, mostly NA and $5-\mathrm{HT}$, by inhibiting their reuptake. ${ }^{4}$

These findings led to the development of the second generation of antidepressive agents, which targeted neurotransmitters reuptake systems and transporters. This very popular class of antidepressants, known as the selective serotonin reuptake inhibitors or SSRIs, was developed trying to find antidepressant agents without the unwanted side effects of the MAOIs or the tricyclics. A typical drug of this generation is Fluoxetine (Prozac) which was discovered and put in the market by 1987 . Drugs of this second generation are better tolerated by the body than those of the first one, but they still present a variety of uncomfortable secondary effects, including slow onset of action, sexual dysfunction, insomnia and weight gain. Thus, there remains a need for more efficient, well-tolerated and more rapidly acting antidepressants. ${ }^{5}$

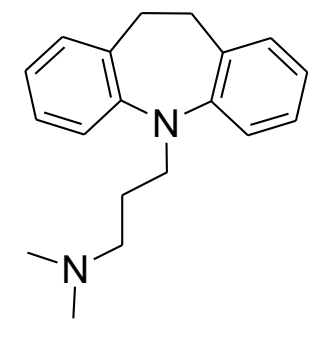

Imipramine

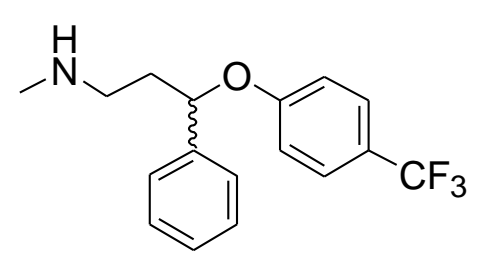

Fluoxetine

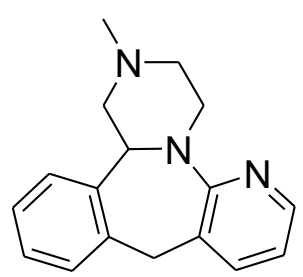

Mirtazapine

Figure 1.- Examples of antidepressants of: first generation, the tricyclic imipramine; second generation, the SSRI fluoxetine; and third generation, the a2-AR antagonist mirtazapine.

The current approach, which represents the third generation, follows the monoamine theory, and consists in new compounds targeting the autoreceptors, specifically the 5-HT receptors such as $5-\mathrm{HT}_{1 \mathrm{~A}}$ or $5-\mathrm{HT}_{1 \mathrm{~B}}$, and the $\mathrm{NA}$ receptor, $\mathrm{a}_{2}-\mathrm{AR} .{ }^{6}$ For example, the negative feedback loop associated with the presynaptic $5-\mathrm{HT}_{1 \mathrm{~A}}$ receptors is considered to be responsible of the interval observed, in many patients, between the administration of SSRIs and the observed therapeutic action. In recent years, the focus seems to have changed to develop compounds with dual action, for example affinity for the 5-HT autoreceptors and inhibitory activity at the 5-HT transporter (SERT), and they seem to be 
the next generation of antidepressants. ${ }^{7}$ Regarding NA autoreceptors, Mirtazapine (Remeron), an $\mathrm{a}_{2}-\mathrm{AR}$ antagonist with blocking action on $5-\mathrm{HT}_{2 \mathrm{~A}}, 5-\mathrm{HT}_{2 \mathrm{~B}}$ and $5-\mathrm{HT}_{3}$, was found and introduced in the market in 1994. Further, the search for dual agents targeting not only the $a_{2}-A R$ but also the NA transporter (NAT) or the SERT is being pursued.

To date, these have been the most typical targets for the development of antidepressant agents and, several reviews have been devoted to these therapies and possible new approaches to the treatment of depression. ${ }^{8,9,10,11}$ Most of the drug discovery efforts have focused on targeting $5-\mathrm{HT}$ or NA systems, trying to improve selectivity, onset or safety, but based mostly on the same mechanisms of action of the older MAO inhibitors and tricyclic antidepressants. Even agomelatine, which is a drug recently authorized targeting the melatonin system, is also a $5-\mathrm{HT}_{2 \mathrm{C}}$ antagonist. ${ }^{12}$ Hence, despite large amounts of money devoted to this research no new medications have appeared in the market. There is no doubt that today's antidepressants are in general safe and effective; however, still there are serious side effects, and less that $50 \%$ of patients show full remission. Therefore, more effective and safer antidepressants with faster onset are still needed. ${ }^{8}$

Although all available antidepressants are attributed to the enhancement of the extracellular availability of 5-HT and/or NA in the brain, the cellular and biochemical mechanisms underlying the therapeutic actions of these drugs remain unclear. Another neurotransmitter that plays a role in mood is dopamine (DA). Dopaminergic agents have been used to manage depression when conventional antidepressant treatments fail, and thus, DA could be involved in the pathophysiology of depression for a subset of patients. ${ }^{13}$ Moreover, chronic treatment with antidepressants produces a number of changes in dopaminergic neurotransmission, in particular a sensitization of behavioural responses to agonists acting at $D A D_{2} / D_{3}$ receptors within the nucleus accumbens. ${ }^{14}$ Additionally, a new and complementary theory is arising, the neurotrophic hypothesis, based on the findings of underdeveloped hippocampus in depressed patients, due to the critical role of neurotrophic factors that control brain development and plasticity. Moreover, it seems that first generation antidepressants and SSRIs act also by increasing these neurotrophic factors and reducing those hippocampus alterations described. ${ }^{15}$

In our search on the worldwide Patent database managed by the European Patent Office (EPO) using the esp@cenet searching engine, ${ }^{16}$ we have found that during the years 2005 to 2008 only very few new targets have been addressed. In the following sections, we will present the results of this search organized in terms of which receptors and/or transporters the patented compounds target. First, those patents related to drugs aiming to monoamine transporters (5-HT and NA) independently or as dual agents will be examined. Secondly, those antidepressants that have been patented as targeting the 
monoamine receptors (singly or in a dual manner) will be discussed. After that a miscellaneous section dealing with those patented drugs that aim to different targets than monoamine systems will be presented.

\section{TARGETING MONOAMINE TRANSPORTERS}

\subsection{Targeting the Serotonin Transporter}

Serotonin (5-hydroxytryptamine, $5-\mathrm{HT}$ ) is a monoamine neurotransmitter that plays an important role in different behaviours including sleep, appetite, memory, and mood. In the synapse, 5-HT can interact with both pre- and postsynaptic receptors. Yet, just after reacting with the receptors, it is important that $5-\mathrm{HT}$ is removed from the synapse. This process, known as reuptake, determines the receptor activation and is performed by the Serotonin Transporter (SERT).

Selective serotonin reuptake inhibitors (SSRIs) act at the SERT and block the reuptake process. Consequently, more $5-\mathrm{HT}$ remains in the cleft where it is free to continue to react with nearby receptors. Considering the monoamine theory for depression already mentioned, SSRIs became the most preferred antidepressant type of drugs for many years, and many of them are in the market. Some known SSRIs currently available include Fluoxetine (Prozac), Paroxetine (Paxil), and Sertraline (Zoloft). Currently attention is moving to different targets, but still a few patents on SSRIs have been issued in the last four years.

Thus, only two patents were issued exclusively on SSRIs during the years 2005-2008. On the one hand, some novel 4-arylpiperidine compounds for the treatment of disorders affecting the central nervous system (CNS), particularly as antidepressants, characterised by having significant affinity and selectivity towards the SERT have been claimed by Nencetti and Lapuci. ${ }^{17}$ On the other hand, Gerdes and Bolstad found some 2'fluoralkyl-6-nitroquipazine that inhibit the SERT an could be used as antidepressant therapeutics. ${ }^{18}$

\subsection{Targeting Serotonin and Noradrenaline Transporters}

In the same way that a reuptake system is required to keep equilibrium in the levels of 5-HT in the synapse, other neurotransmitters such as NA have their own transporters. Again, considering that depression seems to be a consequence of depletion on monoamines (NA and $5-\mathrm{HT}$ ) in the brain, it seems just logical to inhibit both reuptake 
systems increasing the levels of both monoamines in the brain. Hence, to avoid poly therapies, new drugs are aimed to target both transporters at the same time as dual uptake inhibitors (SNRIs). In 1997, American Home Products, Inc. (AHP) released a new antidepressant drug under the name of Venlafaxine (Figure 2), which can be considered as the first SNRI. Its characteristic is its rapid pharmacodynamic response, what is very significant because slow onset is considered one of the most important problems of other modern antidepressants.

In this sense, in 2005 the Shanghai Institute Pharmaceutical company patented a family of aryl alkanol piperazines (Figure 2a) for treating depression. ${ }^{19}$ They claimed that these compounds have excellent dual inhibitory actions to the uptake of both monoamines transporters with minor side effects. To asses the inhibition of both transporters, they used the trial of uptaking the monoamine neurotransmitter by brain synaptosomes. This method is not only used to study the action mechanism of the medicament, but also to look for new antidepressant drugs and they used as control drugs Fluoxetine which is a SSRI and Desipramine which is an inhibitor of NA uptake. Animal depression experiments, such as the Tail Suspension test, were also performed.<smiles>COc1ccc(C(CN(C)C)C2(O)CCCCC2)cc1</smiles>

Venlafaxine<smiles>[R7]C[13CH2]N1CCN(C([R2])C([Y10])O)CC1</smiles>

(a)<smiles>[R][13CH2]N1CC2(CCN([R2])CC2)OC1=O</smiles>

(b)<smiles>[R]NCCC([Y])Oc1ccc([R])cc1</smiles>

(c)

Figure 2.- Venlafaxine and examples of new SNRIs

In 2006 the pharmaceutical company Gruenenthal GmbH developed a series of 1-oxo3,8-diazospiro[4,5]-decan-2-one derivatives ${ }^{20}$ (Figure 2b) as SSRIs and also NA uptake receptor inhibitors. As well, these compounds show a good affinity for the $\mu$-opioid receptor. The in vitro studies to the determination of the 5-HT and NA uptake were developed in rat brain tissue (hypothalamus) and the $\mu$-opioid affinity was determined in human receptors.

In addition, a patent from 2007 reports some 2-(1H-indolylsulfanyl)benzylamine derivative as a compound which has a combined effect of $5-\mathrm{HT}$ reuptake inhibition and $\mathrm{NA}$ reuptake inhibition and is useful as an antidepressant. ${ }^{21}$ 
Finally, a patent on 3-aryloxy-3-substitute propanamines (Figure $2 \mathrm{c}$ ) and their use in inhibiting 5-HT and NA reuptake has been issued last year by Natco Pharma Ltd. ${ }^{22}$ Additionally to the transporter inhibition test, several animal experiments were performed to asses the antidepressant activity of these compounds. Thus, Maximum Tolerance Dose, Gross Behavioural, Force locomotor activity, and Immobility test studies in mice were performed.

In summary, newer dual-acting SNRIs antidepressants appear to possess a more favorable safety and tolerability profile. These drugs also may have an efficacy advantage over SSRIs in treating the painful physical symptoms of depression and in achieving remission of all symptoms of depression.

\subsection{Targeting Serotonin transporter and receptors}

SSRIs have been a big success in treating depression and related illnesses and they have become some of the most prescribed drugs. However, they have a slow onset of action, (taking several weeks to produce full therapeutic effect) and they are effective in less than two-thirds of patients. Moreover, it has been suggested that even though the levels of $5-\mathrm{HT}$ increase by the blockade of SERT, the excess of 5-HT activates the autoreceptors $\left(5-\mathrm{HT}_{1 \mathrm{~A}}\right)$, causing a decrease in $5-\mathrm{HT}$ release in major forebrain areas. ${ }^{23}$ For that reason, a dual agent that blocks SERT and interact with the inhibitory 5-HT autoreceptors will increase even further the levels of the neurotransmitter in the synapse.

Such a multitarget therapy has been strongly pursued by Wyeth Corporation; hence, in the last four years they have produced a large number of patents claiming improved compounds which both inhibit SERT and are antagonists of the 5-HT1A autoreceptor. During 2005 they produced twelve patents on diverse derivatives of heterocycle fused benzodioxanes with different substituents and fused heterocycles in the benzene moiety, some aliphatic chain or cycle containing a tertiary amine attached to the dioxane ring and some other heterocycles attached to this nitrogen containing chain/cycle, $24,25,26,27,28,29,30,31,32,33,34,35$ and two more on phenantrene derivatives related to the benzodioxanes (Figure 3). ${ }^{36,37}$ 
<smiles>[R]c1cc2c(c([Y])c1[X])OC(CN(C)CC(C)CCO)CO2</smiles><smiles>[Y]c1cc2c(c([Y])c1[Y])OC(CN([R2])C(C)CC(C)CCO)CO2</smiles><smiles></smiles>

Figure 3.- Generic structures of the Wyeth benzodioxan based antidepressants

During the next year 2006, they produced eight more patents on this type of heterocycled fused benzodioxanes now containing piperazine or piperidine cycloalkylamines. ${ }^{38,39,40,41,42,43,44,45}$ Between 2007 and 2008, another five patents were produced by Wyeth claiming more heterocycle-fused benzodioxans as dual agents SSRI/5- $\mathrm{HT}_{1 \mathrm{~A}}$ antagonists. ${ }^{46,47,48,49,50}$

In all cases, to determine the affinity of the compounds for the SERT, they followed a protocol similar to that used by Cheetham et. al. ${ }^{51}$ by measuring the compound's ability to displace ${ }^{3} \mathrm{H}$-paroxetine from male rat frontal cortical membranes The high affinity for the $5-\mathrm{HT}_{1 \mathrm{~A}}$ receptor was established by testing the claimed compound's ability to displace $\left[{ }^{3} \mathrm{H}\right] 8$-OHDPAT (dipropylaminotetralin) from the $5-\mathrm{HT}_{1 \mathrm{~A}}$ receptor following a modification of the procedure of Hall et al., ${ }^{52}$ which utilizes $\mathrm{CHO}$ cells transfected with human $5-\mathrm{HT}_{1 \mathrm{~A}}$ receptors.

Other companies such as Merck pursued this line of research and, thus, during 2005 and 2006 they patented two families of compounds that exhibit effects on the inhibition of the 5-HT reuptake and antagonism to the $5-\mathrm{HT}_{1 \mathrm{~A}}$ which are suitable as antidepressants and axiolytics. These compounds were basically indole derivatives and showed selectivity towards the $1 \mathrm{~A}$ subtype over other 5 - HT receptor subtypes. ${ }^{53,54,55}$

In order to avoid polytherapy, the company UCB SA developed two families of 4-amino derivatives that possess the efficacy of SSRIs and have added properties such as blockade of histaminergic $\mathrm{H} 1$ receptors and blockade of serotonin $5-\mathrm{HT}_{2}$ receptors (which seem to be responsible of the sexual side effects of ordinary SSRIs). ${ }^{56,57}$

Several studies have shown that $5-\mathrm{HT}_{4}$ receptors exert a positive modulation on both 5 $\mathrm{HT}$ release and 5-HT neuronal activity. ${ }^{58,59,60,61}$ Thus, Debonnel and Lucas patented in 
2006 that the adjunctive use of a conventional SSRI and a $5-\mathrm{HT}_{4}$ agonist could lead to a faster (4-8 fold) antidepressant action, with improved efficacy. ${ }^{62}$ In this same line of research, Heinrich and Bottcher produced an invention relating to novel indole derivatives with application as antidepressants. It is interesting that they claimed these compounds to exhibit $5-\mathrm{HT}_{1 \mathrm{~A}}$-agonistic actions and an affinity towards the $5-\mathrm{HT}_{4}$ receptor sub-type. ${ }^{63}$

Finally, Pinney and Miranda developed and patented a family of bi-functional organic molecules (3-phenoxy-3-phenylpropyl-4-arylpiperazines) which combine SERT inhibition with $5-\mathrm{HT}_{2 \mathrm{~A}}$ receptor antagonism in one molecular entity. ${ }^{64,65}$

\subsection{Targeting the Serotonin transporter and a2-Adrenoceptors}

Following the idea of increasing the levels of monoamine neurotransmitters in the synapse in a dual target approach to treat depression, another possible approach is to inhibit the SERT and interfere with the adrenergic system by blocking the $a_{2}-A R$ autoreceptor. This tactic seems very interesting since involves two different neurotransmitter systems and it can assure that the levels of NA or 5-HT are always increased in the brain.

In 2005, Janssen Pharmaceutica presented an invention concerning substituted tricyclic isoxazoline derivatives to be used to treat depression, anxiety and psychosis (Figure 4). These compounds have shown to have SSRI activity in combination with additional $a_{2}-A R$ antagonist activity and show a strong antidepressant and/or anxiolytic activity and/or antipsychotic and/or a body weight control activity without being sedative. ${ }^{66}$

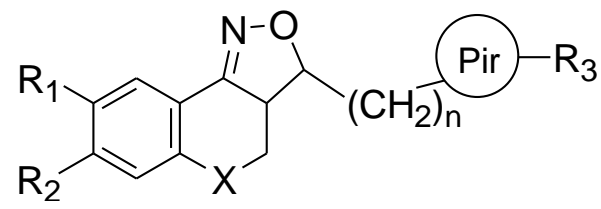<smiles>c1ccc2c(c1)OCC(C1=NCCN1)O2</smiles>

Figure 4.- Janssen's tricyclic isoxazolines (left) and Idazoxan (right)

A couple of patents have been found in the period 2006-2008, claimed by Alpha2 Pharmaceutical, in which the multiple targeting approach involves the administration of racemic or enantiopure $a_{2}-A R$ antagonist Idazoxan (Figure 4 ) in combination with a generic SSRI. This poly-therapy is claimed to produce an improved antidepressant response particularly in the treatment of resistant depressed patients and patients with other metal illnesses such as schizophrenia. ${ }^{67,68}$ 


\subsection{Targeting the Serotonin transporter and other non-Adrenergic receptors}

\subsubsection{Dopamine $D_{2}$ receptor}

Recently, clinical psychiatrists are using antidepressants for the treatment of schizophrenia. Schizophrenia is a mental disorder characterized by impairments in the perception or expression of reality and by significant social or occupational dysfunction. This condition shows two types of symptoms: cognitive, emotional, and behavioural excesses ('positive' symptoms) and deficits ('negative' symptoms) which are somehow related to depression. Positive symptoms of schizophrenia are thought to be consistent with an excessive DA transmission, whereas negative symptoms are more likely to be related to prefrontal abnormalities (lower metabolic activity, i.e. hypofrontality). ${ }^{69}$ In 1997 , the combination of a SSRI, such as fluoxetine, with a dopaminergic antipsychotic agent, such as olanzapine, was described as an improved treatment for psychosis. ${ }^{70}$ Moreover, partial $D_{2}$ receptor agonists have shown a prominent anxiolytic profile in relevant animal models. ${ }^{71}$

Between the years 2005 and 2009, Solvay has patented a large number of compounds that are partial-agonists of the $D_{2}$ receptor and inhibitors of the SERT. These compounds are mostly phenylpiperazine, benzdioxane and tetrahydropyridin-4-yl indole derivatives. ${ }^{72,73,74,75,76,77,78,79,80,81,82,83,84}$ First, they claimed these compounds to be useful for the treatment of psychotic disorders like schizophrenia (treating both positive and negative symptoms), but due to the inhibitory activity of 5-HT reuptake showed by these compounds they claimed that the compounds could also be used for the treatment of CNS conditions caused by disturbances in either the dopaminergic or serotonergic systems, for example depression. They claim that the use of $D_{2}$ partial-agonists provides a flexible modulation of the DA system and prevents the adverse effects caused either by treatment using $D_{2}$ full-agonists like bromocriptine (hallucinations, nausea, vomiting) or $\mathrm{D}_{2}$ full-antagonists like haloperidol (emotional blunting, dysphoria, tardive dyskinesia).

Following this idea, Squibb Bristol Myers have developed compounds having benzene or benzothiazole rings linked to 4-substituted-1,2,5,6-tetrahydropyridine and -piperidine moieties. These compounds possess potent inhibition of 5-HT reuptake and the dopamine $D_{2}$ receptor. It has been described that the combination of a SSRI, such as fluoxetine, with a dopaminergic antipsychotic agent, such as olanzapine, results in an improved treatment for psychosis. ${ }^{70}$ Thus, this company considered that compounds with dopaminergic and serotonergic profiles will be useful in the treatment of psychosis and depression, and maybe other mental illnesses caused by disorders of the dopaminergic and serotonergic systems such as anxiety or obsessive compulsive disorder. ${ }^{85}$ 


\subsubsection{Opioid receptors}

The monoamine reuptake inhibitors used for therapy of depression and anxiety are also used for treatment of chronic pain. It seems that, in addition to the antidepressant actions, SNRIs lead to an independent analgesic action. Monoamine reuptake inhibitors are employed clinically for monotherapy of neuropathic pain, and also as an adjuvant to opiates for treatment of chronic pain. ${ }^{86}$ Considering that chronic pain is accompanied by anxiety or depression in many patients, a compound that can acts as $\mu$-opiate agonist and an inhibitor of SERT and/or NA transporter would be very attractive. Exactly that is what was achieved by Gruenenthal $\mathrm{GmbH}$ with a family of C-(2-phenyl-cyclohexyl)methylamine compounds. ${ }^{87}$

\subsubsection{Neurokinin receptors}

There are three subtypes of Neurokinin receptors $\left(\mathrm{NK}_{1}, \mathrm{NK}_{2}\right.$ and $\left.\mathrm{NK}_{3}\right)$ and the naturally occurring neuropeptides substance $\mathrm{P}$, Neurokinin A, and Neurokinin B are potent agonists for each of them respectively. The interaction of these peptides with their respective receptors is implicated in a range of biological responses including pain transmission and inflammation. ${ }^{88}$ Following a similar approach to the use of combined monoamine transporter inhibitors and opiate agonist, a compound that could act on the regulation of 5-HT and on the Neurokinin receptors could represent a therapeutic advantage. The first group to report the idea of dual SSRI/NK 1 antagonists for the treatment of depression was that of Ryckmans in $2002,{ }^{89}$ and later on, the Servier Laboratories have developed and patented a series of piperazine derivatives as dual SSRIs and Neurokinin antagonists. ${ }^{90}$

With this idea on mind, two patents were found reported by Sanofi Aventis. In 2006, they proposed a new family of indanyl piperazine derivatives that can act as SSRIs and as antagonists of the $\mathrm{NK}_{1}$ receptor. ${ }^{91}$ Later on in 2008, they also patented a poly-therapy combining the use of fluoxetine (a SSRI) and a non-peptidic antagonist of the $\mathrm{NK}_{2}$ receptor (a propanamine derivative ${ }^{92}$ ). ${ }^{93}$

\subsubsection{Cannabinoid receptors}

There are two subtypes of Cannabinoid receptors, $\mathrm{CB}_{1}$, the main target for cannabinoids in the brain, and $\mathrm{CB}_{2}$, and detailed information on these receptors, $\mathrm{CB}_{1}$ receptor modulators, and their pharmacological activities are the subject of recent reviews. ${ }^{94,95,96}$ 
Treatment of the $\mathrm{CB}_{1}$ receptor has strong effects on anxiety and stress-related behaviours suggesting that $\mathrm{CB}_{1}$ ligands might be antidepressant. However, to date, agents that both promote and attenuate $\mathrm{CB}_{1}$ receptor activity have been reported to be beneficial. ${ }^{97}$

Based on the idea of the observed commonality of different mental diseases, the company Solvay patented a series of compounds combining cannabinoid $\mathrm{CB}_{1}$ antagonism with SERT inhibition that could be useful to treat conditions where independently targeting these systems is potentially effective, such as psychosis, anxiety, or depression. They claimed that attacking such disorders simultaneously via two different mechanisms of action can have synergistic effects. ${ }^{98}$

\section{TARGETING MONOAMINE RECEPTORS}

\subsection{Targeting Serotonin receptors}

The 5-HT superfamily of receptors comprises seven different classes $\left(5-\mathrm{HT}_{1}-5-\mathrm{HT}_{7}\right)$ that are split into a total of 14 different subclasses. ${ }^{99}$ In a World Patent Application published in $1995,{ }^{100}$ it was claimed that an antagonist of the 1D subtype of the $5-\mathrm{HT}$ receptor in combination with a $5-\mathrm{HT}_{1 \mathrm{~A}}$ antagonist can be used to treat CNS disorders such as depression and generalized anxiety between other CNS conditions. Moreover, Maura et al. ${ }^{101}$ have stated that administration of agonists selective for $5-\mathrm{HT}_{1 \mathrm{~A}}$ receptors or for both $5-\mathrm{HT}_{1 \mathrm{~A}}$ and $5-\mathrm{HT}_{1 \mathrm{D}}$ receptors might represent a great improvement in the treatment of human cerebellar ataxias, for which there is no established therapy available. These represent some of the many examples evidencing that the $5-\mathrm{HT}$ receptors are suitable targets to increase the monoamine levels in the brain as a therapy for several neuropsychiatric conditions such as depression.

In 2005, Pfizer presented an invention including selective agonists and antagonists of both the $5-\mathrm{HT}_{1 \mathrm{~A}}$ and $5-\mathrm{HT}_{1 \mathrm{D}}$ receptors. These compounds, which are benzo[d]isoxazol-3yl)-octahydropyrido[1,2-a]pyrazin-7-ylpyrimidin-2-yl)amine derivatives (Figure 5a), are useful in treating or preventing migraine, depression and other disorders for which a 5$\mathrm{HT}_{1}$ agonist or antagonist is indicated. ${ }^{102}$

The pharmaceutical company Merck has presented two patents in 2005 with two different families of compounds that can find application as antidepressants between other CNS conditions. The first family consists in 3-oxo-1-propenylazo compounds (Figure 5b) useful as $5-\mathrm{HT}_{2 \mathrm{~A}}$ and/or $5 \mathrm{HT}_{2 \mathrm{C}}$ receptor antagonists, ${ }^{103}$ whereas the second structurally different set of compounds are quinolonyl- or benzopyranonyl-substituted indole derivatives 
(Figure $5 \mathrm{c}$ ) that show agonist activity towards $5-\mathrm{HT}_{1 \mathrm{~A}}$ and $5-\mathrm{HT}_{1 \mathrm{D}}$ receptors and a certain action on the SERT. ${ }^{104}$

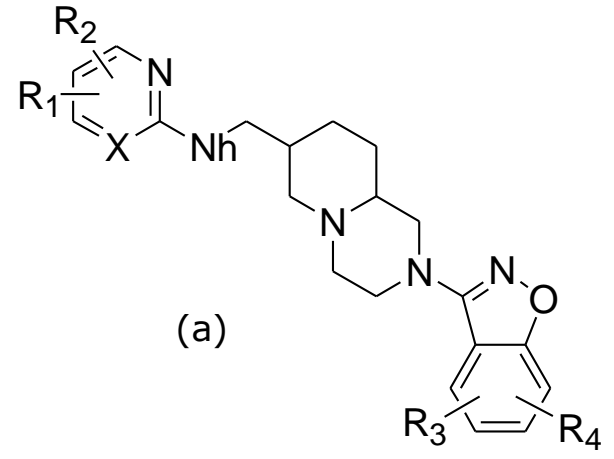<smiles>[R]/C=C/C([R])=O</smiles>

(b)<smiles>[X]O[V]Cc1c[nH]c2c[nH+]ccc12</smiles>

(c)

Figure 5.- Structures patented to aim 5-HT receptors by Pfizer (a) and Merck (b and c)

Targeting 5-HT receptors the pharmaceutical company Esteve have produced several patents with compounds with application in the therapy of depression. In 2006 they issued two patents on tetrahydroisoquinoline substituted sulphonamide compounds (Figure 6a) that act as antagonists of the $5-\mathrm{HT}_{7}$ receptor. ${ }^{105,106}$ This receptor subtype was discovered in 1993 and since then has become a very valuable target. ${ }^{107}$ They are unique in that they show a very low sequence homology with the other 5-HT receptor subtypes (lower than 40\%). Functionally, it is considered to be involved in the regulation of the circadian rhythms and it is known that the interruption of these rhythms is related to CNS disorders such as depression. ${ }^{108}$

In 2007, Esteve produced a different family of compounds, indene derivatives (Figure $6 \mathrm{~b})$, which are claimed to be $5-\mathrm{HT}_{6}$ receptor modulators with application in depression between other conditions. ${ }^{109}$ Compounds with affinity towards $5-\mathrm{HT}_{6}$ receptors are suitable for anxiety and depression as shown by several authors. ${ }^{110,111,112,113,114}$ Moreover, it has been proved that typical and atypical antipsychotics show a high affinity to the $5-\mathrm{HT}_{6}$ receptors. ${ }^{115,116,117,118}$ This would be very relevant in developing dual therapies for the treatment of depression and schizophrenia.<smiles>[R3]c1c([R])c([R2])c2c(c1[R1])C([R5])C([R8])N(C)C2[R5]</smiles>

(a)

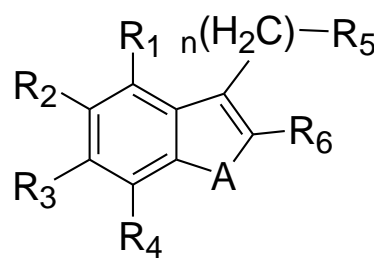

(b)

Figure 6.- Esteve compounds targeting (a) $5-\mathrm{HT}_{7}$ and (b) $5-\mathrm{HT}_{6}$ receptors 
Also targeting $5-\mathrm{HT}_{7}$ receptors the Hungarian Egis Gyogyszergyar Nyilvanosan, in 2007, patented three series of antagonists pyridine and pyperazine derivatives of akyl- and dialkylindoles with application as antidepressant, tranquilizer and other CNS conditions. ${ }^{119,120,121}$ Also in 2007, this company issued another patent dealing with piperazine dialkyloxindole derivatives which antidepressant activity was mediated by the interaction with $5-\mathrm{HT}_{2 \mathrm{C}}{ }^{122}$

Other 5-HT receptor subtypes that have been aimed to develop new antidepressants have been the $5-\mathrm{HT}_{2}$ that are the biological target for two families of compounds developed and patented by Fourtillan SNC during 2008. These are 1-hydroxy-3-oxopropen-1-ylhexahydropyrroloindole and $3 H, 11 H$-oxazolo $\left(3^{\prime}, 4^{\prime}: 1,2\right)$ pyrido $(3,4-b)$ indole derivatives which show agonism by this receptor subtype increasing the serotoninergic signal. ${ }^{123,124}$ Despite the contradictory titles and abstracts (the English title and abstract of the first patent claims that the compounds are $5-\mathrm{HT}_{2}$ antagonist), when reading the original French text, it is clear that both families of compounds act as agonist of the 5$\mathrm{HT}_{2}$ receptor. Yet, this is rather ambiguous since $5-\mathrm{HT}_{2 \mathrm{~A}}$ and $5-\mathrm{HT}_{2 \mathrm{C}}$ subtypes have been described to constitute putative targets in the field of depression, but with distinct underlying mechanisms of action.

\subsection{Targeting $\alpha_{2}$-Adrenoceptors}

Vast research has been performed in the area of serotonin receptors, but investigations centred in the noradrenergic system remain less explored. In particular, it is well known that central noradrenergic transmission is regulated by inhibitory $a_{2}$-ARs autoreceptors which are expressed on both somatodendritic areas and axon terminals. Hence, considering that the activation of these $a_{2}$-ARs induces an inhibition of NA release in the brain, it that has been proposed that depression is associated with a selective increase in the high-affinity conformation of these $a_{2}$-ARs in the human brain. ${ }^{125,126}$ This enhanced $\mathrm{a}_{2}$-AR activity could be implicated in the deficit in noradrenergic transmission described in the aetiology of depression.

Thus, chronic treatment with antidepressants induces an in-vivo desensitization of the $\mathrm{a}_{2}$ ARs regulating the local release of $N A .{ }^{127}$ Thus, the development of selective $a_{2}$ adrenoceptor antagonists can be considered as a new and effective therapeutical approach to the treatment of depressive disorders. It has been demonstrated that the administration of different $a_{2}-A R$ antagonists both locally in the locus coeruleus or systemically increases the release of NA in the prefrontal cortex. ${ }^{128,129}$ Moreover, $a_{2}-A R$ 
antagonists are also able to enhance the increase of NA induced by selective reuptake inhibitor antidepressant drugs. ${ }^{130}$

Prescriptions of the known $\mathrm{a}_{2}-\mathrm{AR}$ antagonist Mirtazapine (Remeron) have increased steadily during the last years. However, this drug still shows unwanted effects such as somnolence, weight gain or dizziness and a long onset of action. Furthermore, in a very recent study it has been shown that only $80 \%$ of depressive patients respond to the current antidepressants and that only a 58\% achieve remission from their condition. ${ }^{131}$ Hence, there is still a need for new antidepressants with fewer secondary effects, faster onset and a better understanding of their action.

In a 2008 patent Rozas et al. claimed guanidine based compounds (guanidine and 2aminoimidazoline, twin and single molecules, Figure 7) which are antagonists of the $a_{2}$ ARs subclass of adrenergic receptors. ${ }^{132}$ The compounds are suitable for the treatment of $\mathrm{a}_{2}$-Ars associated disorders, such as depression or schizophrenia. In vitro assays in human brain tissue to evaluate the $a_{2}-A R$ affinity and functional studies to determine the agonist or antagonist nature of those derivatives with $\mathrm{pK}_{\mathrm{i}}>7$ were designed and performed. Two of the compounds claimed displayed antagonistic properties both in vitro $\left[{ }^{35} \mathrm{~S}\right] \mathrm{GTP} \gamma \mathrm{S}$ binding experiments in human brain tissue and in vivo microdialysis experiments in rats.

During that same year, this team issued another patent relating the antidepressant properties of another guanidine derivative with a good antagonist activity towards $a_{2}-A R$. The antidepressant properties of this compound were evaluated in the Tail Suspension test, which has become one of the most widely used animal models for assessing antidepressant-like activity in mice. The test is based on the fact that animals subjected to the short-term inescapable stress of being suspended by their tail will develop an immobile posture. Antidepressant medications reverse the immobility and promote the occurrence of escape-related behaviour. Notably, at a dose of $10 \mathrm{mg} / \mathrm{kg}$ this guanidine derivative vastly outperforms fluoxetine, even when administered at a dose of 40 $\mathrm{mg} / \mathrm{kg}^{133}$
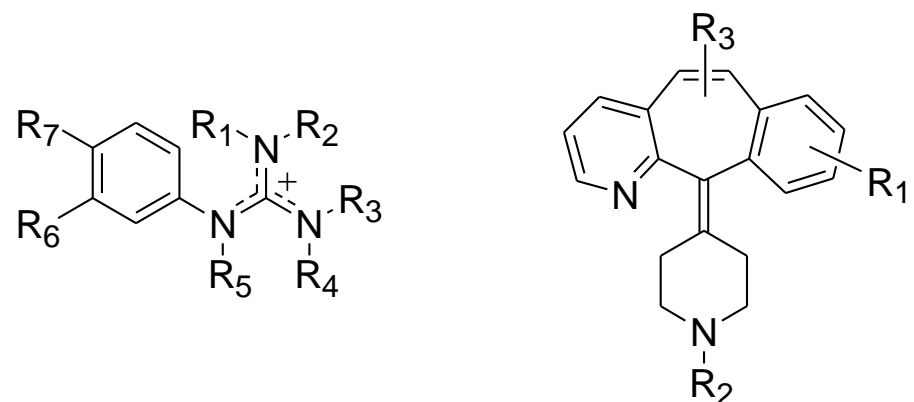

Figure 7.- Amidine-like derivatives developed by Rozas et al. (left) and tricyclic derivative patented by van der Burg (right) 
A patent from 2006 has been found regarding an aromatic, multi-cyclic compound (Figure 7), in which both a pyridine ring and a benzene ring are present and to which is bonded an $\mathrm{N}$-alkyl piperidene group intended for psychotherapeutic and psychiatric treatments. Even though the pharmacological target seems not to be declared, the author mentions that related antidepressants to the object of the patent are Tolvon and Remeron, which are drugs based on respectively mianserin and mirtazapine both known $\mathrm{a}_{2}$-AR antagonists. ${ }^{134}$

Unexpectedly, a family of compounds targeting the $a_{1}-A R$ subtype (and not the $a_{2}-A R$ ) has been patented for the treatment of CNS conditions. These N-substituted 1-benzyl$1 \mathrm{H}$-(1,2,3)-triazole-4-carboxamides are also ligands of the $D_{2}$ and $D_{4}$ dopamine receptors. In general, $a_{1}$-AR antagonists have been considered in the past as good therapies for diseases of the urinary tract (what is also claimed in the patent); however, they cannot be expected to be appropriate for treating depression. ${ }^{135}$

\subsection{Targeting $\alpha 2$-Adrenoceptors and Serotonin receptors}

Among the different classes of auto- and postsynaptic monoamine receptors the $a_{2}-A R$ and the $5-\mathrm{HT}_{2 \mathrm{C}}$ both involved in regulatory mechanisms are highly relevant. It has been shown by different authors that both the dopaminergic and adrenergic transmission is controlled by targeting these receptors. ${ }^{136,137,138,139}$ Based on these findings, in 2005 researchers from Servier developed a series of benzoindole derivatives that were able to act in both the $\mathrm{a}_{2}-\mathrm{AR}$ and the $5-\mathrm{HT}_{2}$ receptor and that have activity as antidepressant, tranquilizer and neuroleptic between other neurological conditions. ${ }^{140}$

\section{TARGETING OTHER SYSTEMS/RECEPTORS}

\subsection{Targeting other CNS receptors}

Glycine is the simplest amino acid and is an important inhibitory neurotransmitter in the brain. Glycine not only has its own receptor (an ion gated channel that conducts chloride anions into the postsynaptic cell), but also binds in a specific site of the NMDA receptor activating the receptor and facilitating the binding of glutamate. Several strategies have been employed as therapeutic approaches to empower NMDA receptor function via activation of the glycine activating site. These include direct interaction with the ligand binding site using agonists such as glycine, and blockade of the glycine reuptake site, 
GlyT1, in order to increase synaptic glycine levels. ${ }^{141}$ In general, glycine receptor agonists/reuptake inhibitors are mainly developed for schizophrenia.

Several patents have been found relating to drugs that interfere with the different glycine neurotransmission pathways and, In one of these patents, glyicine itself is claimed to be useful in combating stress and depression by inhibiting the glycinergic receptor and modulator of the NMDA glutamate receptor. ${ }^{142}$

Sanofi Aventis has produced two patents in 2005 and 2006 on N-heterocyclylmethyl benzamide derivatives with application as therapies for depression (and other CNS conditions) acting as a glycine transporter inhibitor. ${ }^{143,144}$

Considering the importance of glutamate receptors in synaptic activity and plasticity throughout the brain, agents that affect these receptors could exert antidepressant activity. One proposed strategy would be to target any of the metabotropic glutamate receptors. ${ }^{145}$ Thus, glutamate receptors have been addressed as new targets for the treatment of depression. Nakazato and Chaki have prepared novel 2-amino-3-alkoxy-6fluorobicyclo[3.1.0]hexane-2,6-dicarboxylic acid derivatives, which have therapeutic and prophylactic effects on depressive symptoms. These compounds are antagonists of mGluR $_{2}$ and mGluR $_{3}$, which belong to the metabotropic glutamate receptors (mGluR). ${ }^{146}$ Following the same reasoning, Servier have chosen the AMPA receptor of glutamate as target and has developed benzothiazine and benzothiadiazine derivatives which are AMPA modulators for antidepressant new therapies. ${ }^{147,148,149,150}$

Already in the 1950s, it was reported that some anti-infectious agents with NMDA glutamate receptor antagonist activity showed mood uplifting properties thus establishing the relation between the glutamatergic system and depression. ${ }^{151,152}$ Thus, other authors have selected this versatile NMDA receptor as a target for developing new antidepressants. Gozin et al. prepared and patented new hybrid compounds which comprise a fullerene core attached to one or more glutamate receptor ligand residues via a moiety which renders the compounds water soluble and bioavailable under physiological conditions, and they act as NMDA antagonists. ${ }^{153}$ Similarly, Hermann proposed the use of ketamine for treating depression since it is a NMDA antagonist and has also been found to bind to opioid receptors ( $\mu$ type) and sigma receptors. ${ }^{154}$ Choosing a different aminoacid neurotransmitter system, Hatt et al. prepared 1,3dioxane derivatives to enhance the activity of gamma-aminobutyric acid (GABA) receptor and they measure their antidepressant potency in the Tail Suspension test. ${ }^{155}$

Dopamine neurotransmission has been implicated in the pathophysiology of schizophrenia and affective disorders. Even though there is not an agreement on the 
relation of the $D_{3}$ receptors and the serotoninergic activity in the brain different groups have issue a number of patents exploring the effect of targeting $D_{3}$ dopamine receptors on the monoaminergic systems. First, Gmeiner et al. prepared ferrocenecarboxamide derivatives as $D_{3}$ ligands for the treatment of CNS disorders. ${ }^{156}$ In addition, Capet et al. produced different arylpiperazine derivatives with a good inhibition of the $D_{3}$ receptor and therefore application as antidepressants. ${ }^{157,158}$

It has been demonstrated that the inhibition of nicotinic acetylcholine receptors in the brain contributes to the antidepressant effects of amitriptyline. ${ }^{159}$ Based on this finding Binder prepared enantiomerically pure hexahydropyrrolo cyclopentapyridine derivatives, as central nicotine receptor subtype agonists for treating depression. ${ }^{160}$

A new emerging neuroreceptor for analgesics is the vanilloid receptor 1 , and this receptor has found application for the treatment of depression as well. Hence, Gruenenthal GmbH has patented new spiro isoxazole cycloalkane derivatives that target the vanilloid receptor 1 and can find application as antidepressants. ${ }^{161}$

Increasing amounts of data suggest that affective disorders might be related to deregulation of the hypothalamic-pituitary-adrenal axis, and Vasopressin seems to be involved in the regulation of this axis. In Abbott, they have targeted the Vasopressin receptors to develop CNS agents with application in depression, between other conditions, and with this objective have produced a number of substituted oxindole derivatives. ${ }^{162,163}$

Finally, two new targets have been considered useful for the treatment of neuropsychiatric conditions. On the one hand, sigma receptors have been found to be involved in psychosis and other neurological conditions. Most of the studies imply that sigma receptors are membrane receptors involved in signalling transduction. In Esteve Laboratories a family of fused pyrazole derivatives has been prepared as inhibitors of sigma receptors with application in depression. ${ }^{164}$ On the other hand, a sodium/hydrogen exchanger protein has been chosen by Sanofi Aventis as target for substituted 2aminoimidazoles with activity as tranquilizer and antidepressant between other applications. ${ }^{165}$

\subsection{Targeting Melatonin and Melanocortin receptors}

Melatonin (Figure 8) is a naturally occurring hormone, which can be considered an $\mathrm{O}$ methyl acetylated derivative of 5-HT. In fact, its biosynthesis requires the action of serotonin- $\mathrm{N}$-acetyltransferase on $5-\mathrm{HT}$ to form $\mathrm{N}$-acetylserotonin and then $\mathrm{O}$-methylation 
of the hydroxyl group by an O-methyltrasferase. Its biological effects, such as that on the circadian rhythms or light dependence, are a result of interaction with the melatonin receptors. There is enough evidence that the hypothalamic-pituitary-adrenocorticoidal (HPA) system dysfunction is associated with affective disorders and that modifications of circadiadian rhythms are also characteristic of depressed patients. In addition, it is becoming more evident that many of the antidepressants beneficial effects could be achieved through their action on the HPA system. ${ }^{166}$

Thus, drugs that can act in a similar way that melatonin could, in principle, find use as antidepressants. Hence, Lucini et al. produced a patent in 2007 developing novel melatonin ligands (Figure 8), structurally related to melatonin, as antidepressants. ${ }^{167}$ Later on in 2008, Gobbi et al. (researchers from the same group), produced novel derivatives with similar structural features. ${ }^{168}$<smiles>COc1ccc2[nH]cc(CCNC(C)=O)c2c1</smiles>

Melatonin<smiles>COc1ccc2cccc(CCNC(C)=O)c2c1</smiles>

Agomelatin<smiles></smiles><smiles>[R6]Sc1sc2ccc(Br)cc2c1CCNC(C)C</smiles><smiles>CCC(=O)NCC(CO)c1cccc2ccc(OC)cc12</smiles>

Figure 8.- Melatonin, agomelatin and melatonin ligands developed by Lucini/Gobbi et al. (a) and Servier (b and c)

Additionally, Servier has developed three different families of compounds. First they produced some 3-acylaminoethyl-3-phenylthio-benzothiophene derivatives (Figure 8) that act on the $\mathrm{MT}_{1}, \mathrm{MT}_{2}$ or $\mathrm{MT}_{3}$ melatonin receptors and on the 5-HT $2 \mathrm{C}$ receptor subtype as well. ${ }^{169}$ In 2008, they patented new indole derivatives targeting $\mathrm{MT}_{1}$ and $\mathrm{MT}_{2}$ melatonin receptors which seem to be useful to treat sleep disturbance, stress, anxiety and depression between many other disorders. ${ }^{170}$ Finally, they have found new naphthalene derivatives (Figure 8 ) related to the structure of melatonin that bind to melatonin receptors $\mathrm{MT}_{1}$ and $\mathrm{MT}_{2}$ and show antidepressant activity. ${ }^{171}$ 
Agomelatine is a chemical, structurally related to melatonin that acts as an agonist at the melatonin receptors and as an antagonist at $5-\mathrm{HT}_{2 \mathrm{C}}$ receptors. This compound has been tested in the Force Swimming Test for depression showing antidepressant activity and can be considered as a good drug for this condition. ${ }^{12}$ Thus, continuing with their search for new antidepressants, Servier patented the use of agomelatine as antidepressant, neuroleptic and sedative among other CNS applications, ${ }^{172}$ and also as a drug to treat generalised anxiety disorder. ${ }^{173}$ Later on, in 2008, they have also patented the use of agomelatine to treat major and seasonal depression. ${ }^{174}$

Melanocortins are a group of endogenous peptide hormones. Through binding to five melanocortin receptors $\left(M C_{1}-M C_{5}\right)$, these peptides exert multiple influences on the host, including anti-inflammatory and immunomodulatory effects. The $\mathrm{MC}_{4}$ receptor, which is predominantly expressed in the CNS, has become the focus of much attention in recent years because of the critical roles it plays in a wide range of functions, including feeding, sexual behaviour, and stress. Recent development of selective antagonists of this receptor has provided pharmacological evidence that its blockade could be a useful way of alleviating anxiety/depression, pain, and addiction to drugs of abuse. ${ }^{175}$ One patent has been found dealing with 1,2,6-trisubstituted benzimidazole derivatives and imidazopyridine analogues, which are melanocortin $\mathrm{MC}_{4}$ receptor ligands and can be used for the treatment of depression. ${ }^{176}$

Additionally, the work of Chaki et al. on SSRI/MC 4 antagonists should be mentioned. They have developed MCL0042 which is a non-peptidic antagonist of the $\mathrm{MC}_{4}$ receptor and also an inhibitor of the SERT. ${ }^{177}$

\subsection{Targeting enzymatic systems}

Other different targets have been aimed for the development of new antidepressants. For example, Takeda Pharmaceutical has issued two patents describing a series of benzofuranes, which are inhibitors of the protein kinase $B(P K B)$, for the treatment of neuropsychiatric disorders. ${ }^{178,179}$ PKBs are involved in the production of inositol triphosphate $\left(\mathrm{IP}_{3}\right)$ and it has been suggested that a signal transduction from $\mathrm{IP}_{3}$ is involved in nerve cell survival, nerve regeneration or nerve differentiation. However, a relationship between PKB activation and prevention or treatment of depression, anxiety, or manic-depressive psychosis has not been confirmed, and therefore, the actual application of these benzofuranes as antidepressants is doubtful. 
Hyperforin is a flavone which exerts antidepressive and anxiolytic activities on animals and humans. The action mechanisms of this compound are different to those known for antidepressants since they act as MAO inhibitors, on the release of $5-\mathrm{HT}$ and they have a benzodiazepine-like activity. Hyperforin and its derivatives' activity was patented in 2005 by Bombardelli et al. ${ }^{180}$

Other enzymatic system which blockade seems to be useful in antidepressive therapy is the Dipeptidylpeptidase IV (DPPIV). This enzyme is known to have a possible interaction and play essential roles in immune system functioning. Besides, depression has been shown to be accompanied with some immune-inflammatory alterations. Boeringer Ingelheim developed new 2-aminoimidazo(4,5-d)pyridazin-4-one derivatives that are DPP-IV inhibitors and potentially useful as antidepressants. ${ }^{181}$

Anandamide is an endogenous lipid mediator, whose main activity is the activation of cannabinoid receptors. The actions of anandamide are terminated by fatty acid amide hydrolase (FAAH), which is also responsible for the deactivating hydrolysis of other bioactive lipid amides and is a promising target for the treatment of pain, anxiety and depression. FAAH functions via an uncommon Lys-Ser-Ser catalytic triad and carbamic acid aryl esters are potent irreversible FAAH inhibitors exhibiting analgesic, antidepressant-like and anxiolytic-like effects in rodents. ${ }^{182}$ Following this idea, Sanofi Synthelabo have prepared new 1-alkyl-(homo)piperazine-4-carboxylate ester and arylakylcarbamate derivatives that are FAAH inhibitors and show activity as antidepressants. ${ }^{183,184}$

Phosphodiesterases, such as phosphodiesterase-4 (PDE4), are key enzymes that degrade CAMP and their inhibition offers unique opportunities to modify cellular functions related to dementia, depression and schizophrenia. This can indicate that cAMP may play a role in the pathophysiology and pharmacotherapy of depression. ${ }^{185}$ Boehringer Ingelheim has produced new heteroaryl derivatives and new substituted pteridines which are PDE4 inhibitors (Figure 9) and can be useful for the treatment of depression. ${ }^{186,187,188,189}$

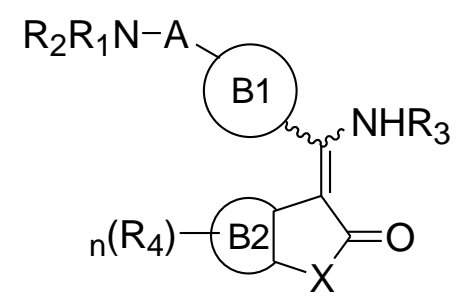<smiles>[R2]c1nc([R])c2nc([R4])c([2H])nc2n1</smiles>

Figure 9.- PDE4 inhibitors developed by Boehringher Ingelheim

Tyrosine hydroxylase is an enzyme that controls the biosynthesis of neurotransmitters in catecholaminergic and dopaminergic neurons. Accordingly, Servier has developed, very 
recently, new triazabenzo[a]naphtho[ $2,1,8-c, d, e]$ azulene derivatives which are tyrosine hydroxylase inducers and therefore increase the levels of monoamines in the brain finding application as antidepressants. ${ }^{190}$

\section{CONCLUSION}

A search on the Worldwide Patent database managed by the European Patent Office (EPO), using the esp@cenet searching engine covering the period 2005-2008, has rendered a total of 106 patents of interest in the area of antidepressants.

Most of the patents found fall in the area of drugs targeting the monoamines' systems, (mostly $5-\mathrm{HT}$ and NA) following the hypothesis of the 'monoamine theory' for depression. Even though, to date, a large amount of research has been done on SSRIs, this continues to be one of the important targets for the therapy of depression. However, during the period analysed many of the patents found deal with compounds targeting not only SSRIs but also, simultaneously, other systems such as the NA reuptake transporter (SNRIs), the 5-HT autoreceptor $\left(5-\mathrm{HT}_{1 \mathrm{~A}}\right)$, the $\mathrm{a}_{2}-\mathrm{AR}$ autoreceptor, and to a lesser extent the $D_{2}$ Dopamine, opioid and neurokinin receptors.

Other receptors being aimed for the development of new antidepressants are the autoreceptors for $5-\mathrm{HT}$ and $\mathrm{NA}\left(5-\mathrm{HT}_{1 \mathrm{~A}}\right.$ and $\left.\mathrm{a}_{2}-\mathrm{AR}\right)$ and other $5-\mathrm{HT}$ receptors that have shown to have an effect on maintaining acceptable levels of monoamines in the brain.

Finally, a miscellaneous group of new targets for depression therapy includes drugs aiming at the Glycininergic system (Glycine receptor and specific site in the NMDA receptor), at the melatonin receptors, inhibitors of a number of enzymes involved in the normal brain processes (PKB, MAO, DPPIV, FAAH, PDE4, Tyr-hydroxylase), and ligands of a number of CNS receptors (Glutamate -AMPA and NMDA, GABA, Dopamine $D_{3}$, nicotinic, vanilloid 1 , vasopressin, $\mathrm{Na} / \mathrm{H}$ exchanger).

In general, a turn towards multiple target drugs is observed in these new patents, probably due to problems concerning efficacy of highly selective drugs emerging from rational drug discovery and genomic programmes.

\section{EXPERT OPINION}

Considering the number of relevant patents produced between 2005 and 2008 (a total of 106) it can be concluded that research in antidepressants continue being a very active 
field. Moreover, taking into account that most of the patents come from pharmaceutical companies (89 out of 106 ) it is safe to say that this is also a very profitable area of research.

In fact, a search in the Medtrack database ${ }^{191}$ yielded information on pharmaceutical companies developing compounds targeting antidepressants. Thus, despite the fact that 323 companies have 1,114 products in the pipeline for depression, most of them target the 5-HT receptors and transporters (SSRIs and SNRIs), and those companies targeting a2-AR are concentrated in developing mirtazapine or its analogue setiptiline. When analysing the potential market size, one finds that in the EU, USA and Japan's 2007 antidepressants sales ( 27 products considered) accounted for more than $€ 10,512$ million. Furthermore, the market predictions for antidepressants ( 7 compounds considered) indicate a decrease in profits (down to $€ 1,967$ million by 2012). This is only for those antidepressants that are SSRIs, because there are two new SNRIs for which an increase of sales is expected by $2011 / 12$ (up to $€ 5018$ million). It seems obvious that those drugs with innovative mechanism of action are expected to be successful.

This seems to indicate certain conservativism in terms of the targets addressed for antidepressants. The monoamine theory of depression is still the only one relatively valid despite being a rather simple hypothesis. All efforts on the therapeutic treatment of depression seem to be concentrated in increasing the levels of 5-HT and NA in the brain, by targeting those transporters and receptors that can be involved in such a regulation, and more specifically the SERT and $5-\mathrm{HT}_{1 \mathrm{~A}}$ autoreceptor. The only novelty seems to be the inclusion of the noradrenergic systems by targeting its transporter and its $a_{2}-A R$ autoreceptor, but the final result continues to be the increasing of monoamine levels.

A new approach, observed from all these patents, is the preparation of multi-targeted drugs, i.e. compounds that target two or more neurotransmitter's receptors and/or transporters. During many years chemists and pharmacologists understood Ehrlich's "magic bullet" concept as a compound that targets a single crucial receptor in an exclusive, highly specific way. However, our present knowledge of many of the CNS conditions, where many factors are involved and interlinked, has changed this paradigm, leading to the development of multi-targeted drugs. The highly selective drugs developed so far have shown to be not effective enough, and hence, it seems that researchers and pharmaceutical companies are devoting many efforts to produce new compounds that target more than one receptor and/or transporter, and even more than one neurotransmitter system.

A few new targets are becoming more relevant even tough many of them were explored around the first two years of the period analyzed and they were not found again in the 
most recent years. Nevertheless, systems such as the melatoninergic, glycinergic, gabaergic or the NMDA receptor are becoming more important and innovative as targets for new antidepressants.

Another relevant issue that is growing in importance is the fact that some clinical psychiatrists are starting to prescribe antidepressants to treat the negative symptoms of schizophrenia. This can be highly relevant for the future in antidepressant research. In the search performed in the Medtrack database it was found that 186 companies have 426 products for schizophrenia in development. From the information available (365 products), it was possible to estimate that $\sim 27 \%$ of these products target DA receptors, $37 \%$ target mixed 5-HT/DA receptors and $11 \%$ do not declare the target. Only two a2AR ligands were found: the antagonist Idazoxan (Houston Pharma, Phase II) which is used as adjunctive therapy for schizophrenia, and the $a_{2 c}-A R$ antagonist ORM10921 (Orion Corporation, Phase I) which is being developed for the treatment of both schizophrenia and depression. Looking at the sales of antipsychotics, even though smaller in number than the antidepressants ( 8 products considered), accounted for more than $€ 11,864$ million. Examining the market predictions for antipsychotic agents (4 products considered), an increment of sales is predicted (up to $€ 1,961$ million by 2011) for those two compounds which FDA approval took place more recently. But a decrease is expected for the rest (down to $€ 2,522$ million by 2012) probably because generics of their active principle are already available.

Thus, we believe that more innovative targets should be explored for the treatment of depression and that new efforts should be devoted to develop drugs that, by targeting CNS neurotransmitter systems in a multi-targeted way, can be used as therapies for both depression and schizophrenia. This will benefit the field in terms of a better understanding of both neuropsychiatric conditions and the interlinked mechanisms involved. It will also be a very profitable and well accepted market approach.

\section{ACKNOWLEDGMENTS}

The author acknowledges the technical assistance of Dr. R. S. Chari with the writing of this manuscript and she thanks the reviewers for their important comments and suggestions. 


\section{REFERENCES}

1.- At: http://www.who.int/mental health/management/depression/definition/en/

2.- Mental Health Global Action Programme. Close the gap, dare to care. Geneva: World Health Organization, 2002

3.- Elhwuegi AS. Central monoamines and their role in major depression. Prog Neuropsychopharmacol Biol Psychiatry 2004; 28:435-451.

4.- Frazer A. Antidepressants. J. Clin. Psychiatr. 1997; 58:9-25.

5.- Millan MJ. The role of monoamines in the actions of established and «novel» antidepressant agents: a critical review. Eur J Pharmacol. 2004; 500:371-384.

6.- Invernizzi RW, Garattini S. Role of presynaptic a2-adrenoceptors in antidepressant action: recent findings from microdialysis studies. Prog Neuro-Psychopharmacol Biol Psychiatry 2004; 28:819-827.

7.- Butler SG, Meegan MJ. Recent development in the design of anti-depressive therapies: Targeting the serotonin transporter. Curr Med Chem 2008; 15:17371761.

8.- Berton O, Nestler EJ. New approaches to antidepressant drug discovery: beyond monoamines. Nat Rev Neurosci 2006; 7:137-151.

9.- Millan MJ. Multi-target strategies for the improved treatment of depressive states: conceptual foundations and neuronal substrates, drug discovery and therapeutic application. Pharmacol Ther 2006; 110:135-370.

10.- Millan MJ. Dual- and triple-acting agents for treating core and co-morbid symptoms of major depression: novel concepts, new drugs. Neurotherapeutics. 2009; 6:53-77.

11.- Rasmussen K. Creating more effective antidepressants: clues from the clinic. Drug Discov Today 2006; 11:623-631.

12.- Bourin M, Mocaer E, Porsolt R. Antidepressant-like activity of S 20098 (agomelatine) in the forced swimming test in rodents: involvement of melatonin and serotonin receptors. J Psychiatry Neurosci 2004; 29:126-133.

13.- Nierenberg AA, Dougherty D, Rosenbaum JF. Dopaminergic agents and stimulants as antidepressant augementation strategies. J Clin Psychiatry 1998; 59(Suppl. 5):60-63.

14.- Willner P. The mesolimbic dopamine system as a target for rapid antidepressant action. Int Clin Psychopharmacol 1997; Suppl. 3:S7-14.

15.- Schmidt HD, Banasr M, Duman RS. Future antidepressant targets: neurotrophic factors and related signaling cascades. Drug Discovery Today: Therapeutic Strategies 2008; 5:151-156.

16.- EPO searching engine: http://ep.espacenet.com/ 
17.- Nencetti S, Lapucci A. 4-Arylpiperidine derivatives and use thereof for preparing a medicament for the treatment of CNS disorders. WO2006106432 (2006).

18.- Gerdes JM, Bolstad DB. Enantiomers of 2'-fluoralkyl-6-nitroquipazine as Serotonin transporter positron emission tomography imaging agents and antidepressant therapeutics. WO2007127262 (2007).

19.- Shanghai Inst. Pharm. Industry. Aralkyl-alcohol piperazine derivatives adn their uses as antgyepressant. US2005267121 (2005).

20.- Gruenenthal GmbH. New substituted 1-oxo-3,8-diazospiro(4.5)-decan-2-one compounds are 5-hydroxy tryptamine uptake receptor inhibitors, useful to treat and/or prevent e.g. pain, migraine, chronic paroxysomal hemicrania, depression and asthma. DE102005030051 (2006).

21.- Lundbeck \& Co As. 2-(1H-indolylsulfanyl)-benzyl amine derivative. P2007277254 (2007).

22.- Natco Pharma Ltd. 3-Aryloxy 3-Substituted Propanamines. WO2008081477 (2008)

23.- Perez V, Gilaberte I, Faries D, et al. Randomised, double-blind, placebo-controlled trial of pindolol in combination with fluoxetine antidepressant treatment. The Lancet 1997; 349:1594-1597.

24.- Wyeth Corp. Antidepressant azaheterocyclylmethyl derivatives of heterocycle-fused benzodioxan methylamines. KR20050061470 (2005).

25.- Wyeth Corp. Antidepressant piperidine derivatives of heterocycle-fused benzodioxans. KR20050042192 (2005).

26.- Wyeth Corp. Antidepressant cycloalkylamine derivatives of heterocycle-fused benzodioxans. KR20050042187 (2005).

27.- Wyeth Corp. Antidepressant indolealkyl derivatives of heterocycle-fused benzodioxan methylamines. KR20050042176 (2005).

28.- Wyeth Corp. Antidepressant arylpiperazine derivatives of heterocycle-fused benzodioxans. MXPA05002743 (2005).

29.- Wyeth Corp. Antidepressant cycloalkylamine derivatives of 2,3-dihydro-1,4benzodioxan. MXPA05002740 (2005).

30.- Wyeth Corp. Antidepressant azaheterocyclylmethyl derivatives of 7,8-dihydro-1,6,9dioxa-3-aza-cyclopenta[a]naphtalene. MXPA03009829 (2005).

31. - Wyeth Corp. Antidepressant (SSRI) azaheterocyclylmethyl derivatives of 7,8dihydro-3H-6,9-dioxa-1,3-diazacyclopenta[a]naphtalene. MXPA03009828 (2005).

32.- Wyeth Corp. Antidepressant azaheterocyclylmethyl derivatives of 2,3-dihydro-1,4dioxino[2,3-f]quinaxoline. MXPA03009826 (2005).

33. - Wyeth Corp. Antidepressant azaheterocyclylmethyl derivatives of oxaheterocyclefused-[1,4]-benzodioxans. MXPA03009825 (2005). 
34.- Wyeth Corp. Antidepressant cycloalkylamine derivatives of 2,3-dihydro-1,4benzodioxans. EP1537103 (2005)

35.- Wyeth Corp. Antidepressant indoletetrahydropyridine derivatives of 2,3-dihydro-7H$[1,4]$ dioxino[2,3-e]indole. WO02088146 (2005).

36.- Wyeth Corp. Antidepressant azaheterocyclylmethyl derivatives of 7,8-dihydro-6H-5oxa-1-aza-phenanthrene. US2005228010 (2005).

37.- Wyeth Corp. Antidepressant azaheterocyclylmethyl derivatives of 1,4,5-trioxaphenanthrene. US2005004209 (2005).

38. - Wyeth Corp. Antidepressant azaheterocyclylmethyl derivatives of heterocycle-fused benzodioxans. ZA200502043 (2006).

39.- Wyeth Corp. Antidepressant cycloalkylamine derivatives of heterocycle-fused benzodioxans. ZA200502047 (2006).

40.- Wyeth Corp. Antidepressant piperidine derivatives of heterocycle-fused benzodioxans. ZA200502042 (2006).

41.- Wyeth Corp. Antidepressant indolealkyl derivatives of heterocyclefused benzodioxan methylamines. ZA200502040 (2006).

42.- Wyeth Corp. Antidepressant azaheterocyclylmethyl derivatives of heterocycle-fused benzodioxans. US2006293301 (2006).

43.- Wyeth Corp. Antidepressant arylpiperazine derivatives of heterocycle-fused benzodioxans. US2006276481 (2006).

44.- Wyeth Corp. Antidepressant cycloalkylamine derivatives of heterocycle-fused benzodioxans. NZ539253 (2006).

45.- Wyeth Corp. Antidepressant cycloalkylamine derivatives of 2,3-dihydro-1,4benzodioxan. US2006160881 (2006).

46.- Wyeth Corp. Antidepressant azaheterocyclylmethyl derivatives of heterocycle-fused benzodioxans. US2007004702 (2007).

47.- Wyeth Corp. Antidepressant heteroaryl derivatives of heterocycle-fused benzodioxans. WO2008150848 (2008).

48.- Wyeth Corp. Antidepressant indolealkyl derivatives of heterocyclefused benzodioxan methylamines. CN101143867 (2008).

49.- Wyeth Corp. Antidepressant arylpiperazine derivatives of heterocycle-fused benzodioxans. CN101239953 (2008).

50.- Wyeth Corp. Antidepressant piperidine derivatives of heterocycle-fused benzodioxans. CN101230066 (2008).

51.- Cheetham SC, Viggers JA, Slater NA, et. al. [3H]Paroxetine binding in rat frontal cortex strongly correlates with [3H]5-HT uptake: Effect of administration of various antidepressant treatments. Neuropharmacol 1993; 32:737-743. 
52.- Hall MD, El Mestikawy S, Emerit MB, et al. [3H]8-Hydroxy-2-(di-npropylamino)tetraline binding to pre- and postsynaptic 5-Hydroxytryptamine sites in various regions of the rat brain. J Neurochem 1985; 44:1685-1696.

53.- Merck Patent GmbH. Derivatives of pyridinalkyl-amonoalkyl-1h-indole inhibiting receptors 5-ht and recapture of serotonin which can be used as antidepressant and anxiolitic. KR20050085038 (2005).

54.- Merck Patent GmbH. Benzofuran oxyethylamines serving as antidepressant drugs and anxiolytic drugs. PL377618 (2006).

55.- Merck Patent $\mathrm{GmbH}$. Indole derivatives as serotonin reuptake inhibitors. MXPA05013538 (2006).

56.- UCB SA. 4-Aminopiperidine derivatives, processes for their preparation and their use as medicaments. MXPA05003290 (2005).

57.- UCB SA. Use of 4-aminoderivatives for the preparation of a medicament for treating neurological diseases. EP1693061 (2006).

58.- Ge JA, Barnes NM. 5-HT4 receptor-mediated modulation of 5-HT release in the rat hippocampus in vivo. $\mathrm{Br} \mathrm{J}$ Pharmacol 1996; 117:1475-1480.

59.- Lucas G, Debonnel G. 5-HT4 receptors exert a frequency-related facilitatory control on dorsal raphe nucleus 5-HT neuronal activity. Eur J Neurosci 2002; 16:817-822.

60.- Lucas G, Compan V, Charnay Y, et al. Frontocortical 5-HT4 receptors exert positive feedback on serotonergic activity: Viral transfections, subacute and chronic treatments with 5-HT4 agonists. Biol Psychiatry 2005; 57:918-925

61.- Lucas G, Rymar VV, Du J, et al. Serotonin(4) (5-HT4) receptor agonists are putative antidepressants with a rapid onset of action. Neuron 2007; 55:712-725.

62.- Debonnel G, Lucas G. Stimulators of 5-ht4 receptors and uses thereof. WO2006029520 (2006).

63.- Heinrich $T$, Bottcher $H$. Indole derivatives as serotonin reuptake inhibitors. US2006160824 (2006).

64.- Pinney KG, Miranda MG. Serotonin reuptake inhibitors. WO2005094896 (2005).

65.- Pinney KG, Miranda MG. Serotonin reuptake inhibitors. US2008132514 (2008).

66.- Janssen Pharmaceutica. C--substituted tricyclic isoxazoline derivatives and their use as anti-depressants. US2005256119 (2005)

67.- Alpha 2 Pharmaceutical. Antidepressant Medicament Comprising Idazoxan and a Selective Serotonin Reuptake Inhibitor. WO2006083204 (2006).

68.- Alpha 2 Pharmaceutical. Antidepressant Medicament Comprising Idazoxan and a Selective Serotonin Reuptake Inhibitor. US2008269306 (2008)

69.- Soares JC, Innis RB. Neurochemical brain imaging investigations of schizophrenia. Biol Psychiatry 1999; 46:600-615. 
70.- Lilly Co Eli. Combination therapy for treatment of psychoses. EP830864 (1997).

71.- Feenstra R, Ronken E, Koopman T, de Vries M, McCreary A, Stoker M, van Charldorp K, Long S, van Scharrenburg G. SLV308. Antiparkinsonian, Antidepressant, Anxiolytic, Dopamine D2 Partial Agonist, 5-HT1A Agonist. Drugs of the Future 2001; $26: 128-132$.

72.- Solvay Pharmaceuticals BV. New phenylpiperazines useful for treating central nervous system disorders caused by dopaminergic or serotonergic systems. NZ523135 (2005).

73.- Solvay Pharmaceuticals BV. Phenylpiperazine derivatives with a combination of partial dopamine-D2 receptor agonism and serotonin reuptake inhibition. US2006122189, US2006122190, US2006247256 (2006).

74.- Solvay Pharmaceuticals BV. Benzdioxane piperazine derivatives with a combination of affinity for dopamine-D2 receptors and serotonin reuptake sites. US2006122175, CA2587940 (2006).

75.- Solvay Pharmaceuticals BV. Phenylpiperazines with a combination of affinity for dopamine-D2 receptors and serotonin reuptakesites. US2006122177. CA2587928 (2006).

76.- Solvay Pharmaceuticals BV. Tetrahydropyridin-4-yl indoles with a combination of affinity for dopamine-D2 receptors and serotonin reuptake sites. US2006122206, CA2587936 (2006).

77.- Solvay Pharmaceuticals BV. Aryloxyethylamine and phenylpiperazine derivatives with a combination of partial dopamine-D2 receptor agonism and serotonin reuptake inhibition. US2006122247 (2006).

78.- Solvay Pharmaceuticals BV. Phenylpiperazine derivatives with a combination of partial dopamine-D2 receptor agonism and serotonin reuptake inhibition. EP1824479, EP1824480, EP1827426, EP1828161, MX2007006818 (2007).

79.- Solvay Pharmaceuticals BV. Benzdioxane piperazine derivatives with a combination of affinity for dopamine-D2 receptors and serotonin reuptake sites. EP1824486, MX2007006758 (2007).

80.- Solvay Pharmaceuticals BV. Tetrahydropyridin-4-yl indoles with a combination of affinity for dopamine-D2 receptors and serotonin reuptake sites. EP1828168, MX2007006757 (2007).

81.- Solvay Pharmaceuticals BV. 8-\{4-[3-(5-fluoro-1H-indol-3-YLI)-propyl]-piperazin-1$\mathrm{YL}$ )-2-methyl-4H-benzo[1,4]oxazin-3-one mesylate with high affinity for the dopamine D2 receptor and the serotonin reuptake site. AU2002250983 (2006). 
82.- Solvay Pharmaceuticals BV. Aryloxyethylamine and phenylpiperazine derivatives with a combination of partial dopamine-D2 receptor agonism and serotonin reuptake inhibition. SI1827427 (2008).

83.- Solvay Pharmaceuticals BV. Phenylpiperazines with a combination of affinity for dopamine-D2 receptors and serotonin reuptake sites. MX2007006756 (2007).

84.- Solvay Pharmaceuticals BV. Phenylpiperazine derivatives with a combination of partial dopamine-D2 receptor agonism and serotonin reuptake inhibition. HR20090015 (2009).

85.- Squibb Bristol Myers Co. Antipsychotic heterocycle compounds. EP1598068 (2005).

86.- Sindrup J. Anesthesia: Biological foundations. Yaksh TL, Lynch C, Zapol W, et al. Philadelphia: Lippincott-Raven, 1997.

87.- Gruenenthal GmbH. C-(2-phenyl-cyclohexyl)-methylamine compounds for the treatment of anxiety disorder. US2006258741 (2006).

88.- Maggi CA. The troubled story of tachykinins and neurokinins.Trends Pharmacol Sci $2000 ; 21: 173-175$.

89.- Ryckmans T, Balançon L, Berton O, et al. First dual NK1 antagonists serotonin reuptake inhibitors: synthesis and SAR of a new class off potential antidepressants. Bioorg Med Chem Lett 2002; 12:261-264.

90.- Servier Lab. Piperazine derivatives and their use as serotonin reuptake inhibitors or as neurokinin antagonists. EP1710240 (2006).

91.- Sanofi Aventis. Indanyl-piperazine derivatives, process for their preparation and pharmaceutical compositions containing them. EP1707564 (2006).

92.- Edmonds-Alt X, VIlain P, Goulaouic $P$, et al. A potent and selective non-peptide antagonist of the neurokinin a(NH2) receptor. Life Sciences 1992; 50:PL101-PL106.

93.- Sanofi Aventis. Composition useful to treat e.g. anxiety disorder comprises (S)-(-)$\mathrm{N}$-(4-(4-acetamido-4-phenyl-1-piperidyl)-2-(3, 4-dichlorophenyl) butyl)-Nmethylbenzamide, (+/-)-N-methyl-3-phenyl-3-(4-(trifluoromethyl)phenoxy)-propan1-amine. FR2904221 (2008).

94.- Padgett LW. Recent developments in cannabinoid ligands. Life Sciences 2005; 77:1767-1798.

95.- Muccioli GG, Lambert DM. Current knowledge on the antagonists and inverse agonists of cannabinoid receptors. Curr Med Chem 2005; 12:1361-1394.

96.- Lambert DM, Fowler CJ. The endocannabinoid system: Drug targets, lead compounds, and potential therapeutic applications. J Med Chem 2005; 48:50595087.

97.- Viveros MP, Marco EM, File SE. Endocannabinoid system and stress and anxiety responses. Pharmacol Biochem Behav 2005; 81:331-342. 
98.- Solvay Pharmaceuticals BV. Compounds with a combination of cannabinoid cb1 antagonism and serotonin reuptake inhibition, US2008214559, WO2008084057 (2008).

99.- Hoyer D, Martin G. 5-HT receptor classification and nomenclature : towards a harmonization with the human genome. Neuropharmacology 1997; 36:419-428.

100.- SmithKline Beecham PLC, Jones BJ, Routledge C. Composition Containing 5-HT1A and 5-HTID antagonists. WO9531988 (1995).

101.- Maura G. Serotonin 5-HT1D and 5-HT1A receptors respectively mediate inhibition of glutamate and inhibition of cyclic GMP production in rat cerebellum in vitro. J Neurochem 1996; 66:203-209.

102.- Pfizer Prod. Inc. 5HT1 antagonists for antidepressant therapy. OA11742 (2005).

103.- Merck Patent GmbH. New 3-oxo-1-propenyl azo compounds useful as 5-HT receptor antagonists e.g. for treating psychoses, neurological disorders, amyotrophic lateral sclerosis and eating disorders. DE10360151 (2005).

104.- Merck Patent GmbH. New quinolonyl- or benzopyranonyl-substituted indole derivatives are $5 \mathrm{HT}(1 \mathrm{~A})$ - and/or 5HT(1D)-agonists useful e.g. as anxiolytic, antidepressant, neuroleptic and/or antihypertensive agents. DE10353657 (2005).

105.- Esteve Labor Dr. New tetrahydroisoquinoline substituted sulfonamide compounds useful as 5-HT7 receptor antagonist in the treatment of e.g. central nervous system disorders. ES2257168 (2006).

106.- Esteve Labor Dr. New dihydro-1H-isoquinoline compounds are 5hydroxytryptamine-7 inhibitors useful for the treatment of e.g. sleep disorder, shift worker syndrome, depression, migraine, anxiety, psychosis, schizophrenia and pain. ES2257167 (2006).

107.- Terrón JA. The 5HT7 receptor: A target for novel therapeutic avenues? IDrugs $1998 ; 1: 302-310$.

108.- Lovenberg TW, Baron BM, de Lecea L, et al. A novel adenylyl cyclase-activating serotonin receptor (5-HT7) implicated in the regulation of circadian rhythms. Neuron 1993; 11:449-458.

109.- Esteve Labor Dr. New indene derivatives useful for treating e.g. obesity, bulimia, anorexia, cachexia, diabetes, anxiety, panic attacks, depression and bipolar disorders. ES2274725 (2007).

110.- Yoshioka M, Matsumoto $M$, Togashi $H$, et al. Central distribution and function of 5 HT(6) receptor subtype in the rat brain. Ann NY Acad Sci 1998; 861:244-244.

111.- Bourson A, Boess FG, Bos $M$, et al. Involvement of 5-HT6 receptors in nigro-striatal function in rodents. $\mathrm{Br}$ J Pharmacol 1998; 125:1562-1566. 
112.- Rogers DC, Robinson TL, Quilter $C A$, et al. Cognitive enhancement effects of the selective 5-HT6 antagonist SB-271046. Br J Pharmacol Suppl. S 1999; 127:22P.

113.- Branchek TA, Blackburn TP. 5-HT6 receptors as emerging targets for drug discovery. Annu Rev Pharmacol Toxicol 2000; 40:319-334.

114.- Routledge C, Bromidge SM, Moss SF, et al. Characterization of SB-271046: A potent, selective and orally active 5-HT6 receptor antagonist. Br J Pharmacol 2000; 130:1606-1612.

115.- Roth BL, Craigo SC, Choudhary MS, et al. Binding of typical and atypical antipsychotic agents to 5-hydroxytryptamine-6 and 5-hydroxytryptamine-7 receptors. J Pharmacol Exp Ther 1994; 268:1403-1410.

116.- Glatt CE, Snowman AM, Sibley DR, et al. Clozapine - selective labeling of sites resembling 5 ht(6) serotonin receptors may reflect psychoactive profile. Mol Med $1995 ; 1: 398-406$.

117.- Monsma FJ, Shen Y, Ward RP, et al. Cloning and expression of a novel serotonin receptor with high-affinity for tricyclic psychotropic-drugs. Mol Pharmacol 1993; 43:320-327.

118.- Shinkai T, Ohmori O, Kojima H, et al. et al. Association study of the 5-HT6 receptor gene in schizophrenia. Am J Med Genet 1999; 88:120-122.

119.- Egis Gyogyszergyar Nyilvanosan. Pyridine derivatives of alkyloxindoles as 5-HT7 receptor active agents. HU0500462 (2007).

120.- Egis Gyogyszergyar Nyilvanosan. Pyperazine derivatives of alkyl-oxindoles. HU0500461 (2007).

121.- Egis Gyogyszergyar Nyilvanosan. Pyridine derivatives of dialkyl-oxindoles. HU0500463 (2007)

122.- Egis Gyogyszergyar Nyilvanosan. Piperazine derivatives of dialkyl-oxindoles. HU0500464 (2007)

123.- Fourtillan SNC. New 1-hydroxy-3-oxo-propen-1-yl-hexahydro-pyrrolo-indole compounds are 5-hydroxy tryptamine-2 receptor antagonists useful to treat e.g. depression, anxiety, Parkinson's disease, Alzheimer's diseases, cancer, skin diseases and anxiety. FR2912747 (2008).

124.- Fourtillan SNC. New $3 \mathrm{H}, 11 \mathrm{H}$-oxazolo(3',4':1,2)pyrido(3,4-b)indole derivatives are 5-hydroxytryptamine-2 receptor activators useful e.g. to treat insomnia, jet lag, anxiety, depression and Alzheimers. FR2908767 (2008).

125.- Callado LF, Meana JJ, Grijalba B, et al. Selective increase of alpha2a-adrenoceptor agonist binding sites in brains of depressed suicide victims. J Neurochem 1998; 70:1114-1123. 
126.- Gonzalez-Maeso J, Rodriguez-Puertas R, Meana JJ, et al. Neurotransmitter receptor-mediated activation of G-proteins in brains of suicide victims with mood disorders: Selective supersensitivity of alpha2A-adrenoceptors. Mol Psychiatry 2002; 7:755-767.

127.- Mateo Y, Fernandez-Pastor B, Meana JJ. Acute and chronic effects of desipramine and clorgyline on alpha2-adrenoceptors regulating noradrenergic transmission in the rat brain: A dual-probe microdialysis study. $\mathrm{Br}$ J Pharmacol 2001; 133:1362-1370.

128.- Fernandez-Pastor $B$, Meana JJ. In vivo tonic modulation of the noradrenaline release in the rat cortex by locus coeruleus somatodendritic alpha2-adrenoceptors. Eur J Pharmacol 2002; 442:225-229.

129.- Devoto P, Flore G, Pani L, Gessa GL. Evidence for co-release of noradrenaline and dopamine from noradrenergic neurons in the cerebral cortex. Mol Psychiatry 2001; 6:657-664.

130.- Mateo Y, Pineda J, Meana JJ. Somatodendritic alpha2-adrenoceptors in the locus coeruleus are involved in the in vivo modulation of cortical noradrenaline release by the antidepressant desipramine. J Neurochem 1998; 71:790-798.

131.- Hennings JM, Owashi T, Binder EB, et al. Clinical characteristics and treatment outcome in a representative sample of depressed inpatients - Findings from the Munich Antidepressant Response Signature (MARS) project. J Psychiatr Res 2009; 43:215-229

132.- Rozas I, Rodriguez F, et al. Guanidine based Compounds. EP2008068199 (2008).

133.- Rozas I, Rodriguez F, et al. a2-Adrenoceptor Ligands. UK08234205 (2008).

134.- Van Der Burg WJ. Psychofarmaceutical Preparation. WO2006006858 (2006).

135.- Gmeiner P, Huebner $H$. New N-substituted 1-benzyl-1H-(1,2,3)-triazole-4carboxamides, are dopamine and alpha-1 adrenergic receptor ligands useful for treating diseases of the urinary tract, vascular system or CNS. DE102004039065 (2006).

136.- Millan MJ, Bervoets K, Rivet JM, et al. Multiple alpha-2-adrenergic receptor subtypes .2. Evidence for a role of rat r(alpha-2a), adrenergic-receptors in the control of nociception, motor behavior and hippocampal synthesis of nor adrenaline. J Pharmacol Exp Ther 1994; 270:958-972.

137.- Millan MJ, Gobert A, Rivet JM, et al. Mirtazapine enhances frontocortical dopaminergic and corticolimbic adrenergic, but not serotonergic, transmission by blockade of alpha(2)-adrenergic and serotonin(2C) receptors: a comparison with citalopram. Eur J Neurosci 2000; 12:1079-1095.

138.- Gobert A, Di Cara B, Cistarelli L, et al. Piribedil enhances frontocortical and hippocampal release of acetylcholine in freely moving rats by blockade of alpha(2A)- 
adrenoceptors: A dialysis comparison to talipexole and quinelorane in the absence of acetylcholinesterase inhibitors. J Pharmacol Exp Ther 2003; 305:338-346.

139.- Kennett GA, Wood MD Bright F, et al. SB 242084, a selective and brain penetrant 5-HT2C receptor antagonist. Neuropharmacology 1997; 36:609-620.

140.- Servier Lab. Benzoindoline derivatives with adrenergic activity. EP1516871 (2005).

141.- Kinney GG, Sur C. Glycine site modulators and glycine transporter-1 inhibitors as novel therapeutic targets for the treatment of schizophrenia. Curr Neuropharmacol 2005; 3:35-43.

142.- Tech Egon. Combating stress states or nervous system or metabolic disorders, using glycine as neurotransmission modulator showing antistress, stress protective, nootropic and toxin binding actions. DE102005027905 (2005).

143.- Sanofi Aventis. New N-heterocyclylmethyl benzamide derivatives useful as glycine transporter inhibitors for e.g. treating dementia-associated behavioral problems, psychoses, anxiety, depression and alcohol abuse. FR2861076 (2005).

144.- Sanofi Aventis. Use of tricyclic compounds as glycine transport inhibitors. CN1882587 (2006).

145.- Swanson CJ, Bures M, Johnson MP, et al. Metabotropic glutamate receptors as novel targets for anxiety and stress disorders. Nature Rev Drug Discov 2005; 4:131144.

146.- Nazakato A, Chaki S. 6-Fluorobicyclo[3.1.0]hexane derivatives. US2005119345 (2005).

147.- Servier Lab. Fluorinated benzothiadiazine derivatives and their use as AMPA receptor modulators. EP1557412 (2005).

148.- Servier Lab. Benzothiazine and benzothiadiazine derivatives, process for their preparation and phamaceutical compositions containing them. EP1669072 (2006).

149.- Servier Lab. Benzothiadiazine derivatives, method for preparing them and pharmaceutical compositions containing them. EP1655030 (2006).

150.- Servier Lab. Benzothiadiazine derivatives, process of preparation thereof and pharmaceutical compositions containing them. EP1655299 (2006).

151.- Sanacora G, Rothman DL, Mason G, Krystal JH. Clinical studies implementing glutamate neurotransmission in mood disorders. Ann NY Acad Sci 2003; 1003:292308.

152.- Paul IA, Skolnick P. Glutamate and depression: clinical and preclinical studies. Ann NY Acad Sci 2003; 1003:250-272.

153.- Gozin M, Weiner HL. Novel neuroprotective compounds and uses thereof. WO2006077597 (2006). 
154.- Hermann HL. Use of S-(+)-ketamine for treating depression, which is therapyrefractive depression, preferably depressive episode, relapsing disorder and bipolar affective disorder. DE102007009888 (2008).

155.- Hatt $H$, Kragler $A$. Use of 1,3-dioxane derivatives to enhance the activity of gamma-aminobutyric acid (GABA) on GABA-A receptors. DE102007010077 (2008).

156.- Sanol Arznei Schwarz GmbH. Ferrocenecarboxamide derivatives for use as dopamine D3 ligands for the treatment of CNS disorders. EP1733727 (2006).

157.- Bioproject Soc Civ Ile. New arylpiperazine derivatives, useful to prevent and/or treat neuropsychiatric disorders e.g. disorders of drug dependence, sexual disorders and motor disturbance, are dopamine D3 receptor ligands. FR2878524 (2006).

158.- Bioproject Soc Civ Ile. Arylpiperazuine derivatives as selective ligand for the dopamine D3 receptor. EP1659112 (2006).

159.- Caldarone $B J$, Harrist $A$, Cleary $M A$, et al. High affinity nicotinic acetylcholine receptors are required for antidepressant effects of amitriptyline on behavior and hippocampal cell proliferation. Biological Psychiatry 2004; 56:657-664.

160.- Binder Eva Dkfm. New enantiomerically pure hexahydro-pyrrolo-cyclopentapyridine derivatives, useful as central nicotine receptor subtype agonists for e.g. treating Alzheimer's or Parkinson's disease, anxiety and depression. AT414305 (2006).

161.- Gruenenthal GmbH. New spiro-isoxazole-cycloalkane compounds, useful as vanilloid receptor 1 ligands for treating e.g. pain, depression and neurodegeneration. DE102005044814 (2006).

162.- Abbott GmbH \& Co. KG. New substituted oxindole derivatives are vasopressin receptor binders useful to treat e.g. diabetes insipidus, enuresis nocturna, incontinence, hypertonia, heart failure, myocardial infarction, coronary spasm and renal disorders. DE102005015957 (2006).

163.- Abbott $\mathrm{GmbH} \&$ Co. KG. New substituted oxindole derivatives are vasopressin receptor binders useful to treat e.g. diabetes insipidus, enuresis nocturna, incontinence, hypertonia, heart failure, myocardial infarction, coronary spasm and renal disorders. DE102005014628 (2006).

164.- Esteve Labor. Dr. New fused pyrazole derivatives, useful for treatment of psychosis and pain, are sigma receptor inhibitors. ES2251317 (2006).

165.- Sanofi Aventis Deutschland. Substituted 2 amino imidazoles, method for their manufacture and their use as a drug or diagnostic and drug containing them. EP1857445 (2007). 
166.- Barden N, Shink E, Labbe M, et al. Antidepressant action of agomelatine (S 20098) in a transgenic mouse model. Prog Neuropsychopharmacol Biol Psychiatry 2005; 29:908-916.

167.- Lucini V, Spadoni G. Novel melatonin ligands having antidepressant activity as well as sleep inducing properties. CA2636601 (2007)

168.- Gobbi G, Mor M. Novel elatonin ligands having antidepressant activity as well as sleep inducing properties. EP1973868 (2008).

169.- Servier Lab. New 3-acylaminoethyl-3-phenylthio-benzothiophene derivatives, are melatonin receptor ligands useful e.g. for treating sleeping disorders, anxiety, depression, jet lag or appetite disorders. FR2857011 (2005).

170.- Servier Lab. New indole derivatives are melatonin receptor binders useful to treat e.g. sleep disturbance, stress, anxiety, depression, cardiovascular diseases, digestive system disorders, schizophrenia, panic attack, obesity and insomnia. FR2907452 (2008).

171.- Servier Lab. New naphthalene derivatives, method of preparing same and pharmaceutical compositions containing them. EP1873140 (2008).

172.- Servier Lab. Use of agomelatin in the manufacture of a medicament for the treatment of bipolar disorders. EP1714647 (2006).

173.- Servier Lab. Use of agomelatine to obtain a medication aimed at treating generalised anxiety disorder. EP1842535 (2007).

174.- Servier Lab. Use of agomelatine to obtain a drug to treat Smith Magenis syndrome, major depression, seasonal depression, sleep disorder, cardiovascular disease, digestive system disorder, insomnia, shiftlag, appetite disorders and obesity. FR2908995 (2008).

175.- Chaki S, Okuyama S. Involvement of melanocortin-4 receptor in anxiety and depression. Peptides 2005; 26:1952-1964.

176.- Poitout L, Brault V. New 1,2,6-trisubstituted benzimidazole derivatives and imidazo-pyridine analogs, are melanocortin receptor ligands useful for treating e.g. obesity, cachexia, anxiety, depression or neuropathic pain. FR2862971 (2005).

177.- Chaki S, Oshida Y, Ogawa S, et al. MCL0042: a nonpeptidic MC4 receptor antagonist and serotonin reuptake inhibitor with anxiolytic- and antidepressant-like activity. Pharmacol Biochem Behav 2005; 82:621-626.

178.- Takeda Pharmaceutical. Antidepressant. PL371366 (2005).

179.- Takeda Pharmaceutical. Antidepressant. US2006241168 (2006).

180.- Bombardelli E, Morazzoni P. Use of hyperforin derivatives as an antidepressant agent. EP1607099 (2005). 
181.- Boehringer Ingelheim Pharma. New 2-amino-imidazo(4,5-d)pyridazin-4-one derivatives are dipeptidyl-peptidase IV inhibitors useful in the treatment of e.g. diabetes mellitus, autoimmune disease, rheumatoid arthritis, and multiple sclerosis. DE102004025552 (2005).

182.- Lodola A, Mor M, Rivara S, et al. Identification of productive inhibitor binding orientation in fatty acid amide hydrolase (FAAH) by QM/MM mechanistic modeling. Chem Commun 2008; 214-216.

183.- Sanofi Synthelabo. New 1-alkyl-(homo)piperazine-4-carboxylate ester derivatives, are fatty acid amidohydrolase inhibitors useful e.g. for treating pain, cancer or neurodegenerative, cardiovascular, inflammatory or allergic disease. FR2866888 (2005).

184.- Sanofi Synthelabo. Derivatives of arylalkylcarbamates, process for their preparation and therapeutic application thereof. EP1972616 (2008).

185.- Halene TB, Siegel SJ. PDE inhibitors in psychiatry - future options for dementia, depression and schizophrenia? Drug Discovery Today 2007; 12:870-878.

186.- Boehringer Ingelheim Pharma. New heteroaryl derivatives are phosphodiesterase4 enzyme inhibitors useful for the treatment of e.g. respiratory or gastrointestinal complaints or diseases, depression, Alzheimer's disease and Parkinson's disease. DE102005023207 (2006).

187.- Boehringer Ingelheim Pharma. New heteroaryl derivatives are phosphodiesterase-4 enzyme inhibitors useful for the treatment of e.g. respiratory or gastrointestinal complaints or diseases, depression, Alzheimer's disease and Parkinson's disease. DE102005019718 (2006).

188.- Boehringer Ingelheim Pharma. New heteroaryl derivatives are phosphodiesterase-4 enzyme inhibitors useful for the treatment of e.g. respiratory or gastrointestinal complaints or diseases, depression, Alzheimer's disease and Parkinson's disease. DE102005035575 (2007).

189.- Boehringer Ingelheim Pharma. New substituted pteridine compounds, useful as phosphodiesterase 4 inhibitors for treating e.g. inflammatory diseases, cancer, asthma, ulcerative colitis, depression and schizophrenia. DE102004057645 (2006).

190.- Servier Lab. New triazabenzo(a)naphtho(2,1,8-cde)azulene derivatives useful as tyrosine hydroxylase inducers, e.g. for treating depression or anxiety. FR2911141 (2008).

191.-Medtrack, http://www.medtrack.com/research/default.asp, Life Science Analytics Inc. 